DOI https://doi.org/10.18551/rjoas.2017-07.12

\title{
USING OF YOUTUBE AND FACEBOOK TO MAXIMIZE DIGITAL ERA ADVERTISING
}

\author{
Chandra Yakob Utama \\ Information System Department, Bina Nusantara University, Jakarta, Indonesia \\ E-mail: yakob@binus.ac.id
}

\begin{abstract}
The aims of this research were to know: the usage of YouTube and Facebook Advertisement, the effectiveness of YouTube and Facebook Advertisement, and how to maximize the usage of YouTube and Facebook Advertisement. This research was using qualitative research method. Jenny Doan, the founder of Missouri Star Quilt Company has more than 400 employees, capable to send more than 5000 units of its products daily with more than 14 quilting shops in Hamilton small town and Missouri. The using of video through targeted YouTube Advertisement could reach 1 million of future customers and sell 14,000 products within first six months. RevZilla have had its video watched for 7 million times and increased its income by $50 \%$ in the last year. LSTN Headphones had utilized YouTube Advertisement as the means to introduce its products globally. Its popularity had made LSTN Headphone capable of giving gifts to more than 20,000 people around the world. Heniken Taiwan had increased its market share in three months after using Facebook Advertisement as much as 100 basis point. It also increased its sale as much as $4 \%$ compared to the previous year and received Brand Equity Score of 8.66. Lazada could increase its order for more than $59 \%$ and increase the advertisement awareness by $15 \%$. Carousell had increased product offering as much as $53 \%$ and decrease the act cost for promotion as much as $57 \%$. YouTube and Facebook Advertisement are the suitable means of promotion that can be utilized to increase the result of promotion.
\end{abstract}

\section{KEY WORDS}

YouTube, Facebook, advertisement, digital era, trade.

Rapid development of technology had made most of business to utilize digital media as marketing strategy for their goods and services. Although the traditional marketing ways are still exist and done, with the support of digital technology the targeted area will be wider. The traditional ways of product promotions such as billboard, banner, newspaper, radio, brochure, and television can only reach particular area.

By using the support of digital technology and internet network, promotions can be done in modern ways with the world wide range. Promotion through web advertising is a suitable choice to introduce the products to the worldwide. Moreover, the usage of internet through digital technology such as smartphone, computer, and laptop are increasing. Marketing in digital era is not only to develop the product, price, and product availability, but also communication with the customer that will open more opportunities of product sales (Machfoedz, 2010). There are some ways to increase the product sale, such as advertising, direct marketing, sales promotion, personal selling, public relations, and internet marketing (Machfoedz, 2010).

YouTube is a social media in form of video show which is one of Google's products. YouTube user can share videos to other users by uploading the video to his/her account (Fitzgerald, 2015). User who has uploaded his/her video is given copyright options and content license. The other rights are right to reproduce, distribute, preparing derivative creations of the video, and promoting. The usage rights will be stopped if the used material had been deleted (Kanggas, 2007). Besides that, a registered YouTube user could give his/her comments to a video he/she had watched, so that it can be a feedback to other user and the video owner (Kanggas, 2007). YouTube has a really big channel in the world. Even Hollywood is now using YouTube to publish its newest videos or trailers (Kanggas, 2007). By 
the large number of YouTube users around the world, video advertisement is one of the superior services for the company that wants to increase its market target.

Facebook is also one of social media sites that have large number of users around the world. With more than 500 million of users around the world, Facebook is not only a tool to make friends and to communicate, but also serves as marketing tool for business through easy and economic ways (Graham and Curran, 2011).

The problems investigated in this research are: 1) how is the using of YouTube and Facebook Advertisement?, 2) how is the effectiveness of YouTube and Facebook Advertisement, and 3) how to maximize the using of YouTube and Facebook Advertisement?

The aims of this research are to know: (1) the using of YouTube and Facebook Advertisement, (2) the effectiveness of YouTube and Facebook Advertisement using, and (3) how to maximize the usage of YouTube and Facebook Advertisement.

\section{METHODS OF RESEARCH}

In this research, the researcher used qualitative research method. Qualitative research is related to arguments, experiences, and individual feelings that create subjective data. Qualitative research describes social phenomena that occur naturally. There is no situation manipulation in the study as can be done in qualitative research method. It depends on the skill of data identification which is used to develop the concepts and theories in order to understand the social world. Qualitative research used existing data and supported by relevant previous researches to be analyzed so that a new concept is created (Hancock et al., 2007). This method was used because of some limitations in the study, such as incomplete data and insufficient variables in the study (Yin, 2011).

\section{RESULTS AND DISCUSSION}

Using of YouTube Advertisement. By using YouTube Advertisement, there are many increased product sales and new customers are appearing from around the world. Missouri Star Quilt Company was a small blanket store which is finally developed because of YouTube Advertisement. Jenny Doan as the founder of Missouri Star Quilt Company has more than 400 employees and sends more than 5000 units of its products daily from more than 14 quilting stores in Hamilton small town and Missouri. The usage of video Advertisement through targeted YouTube Advertisement managed to reach 1 million of future customers and sell 14,000 units of the products within the first six months. Jenny Doan knows that there are many people who look for a video with "how to make a blanket" keyword so that she is focused on the tutorial of how to make it. Her video in YouTube had reached more than 360,000 subscribers and more than 95 million watches (YouTube, 2017a).

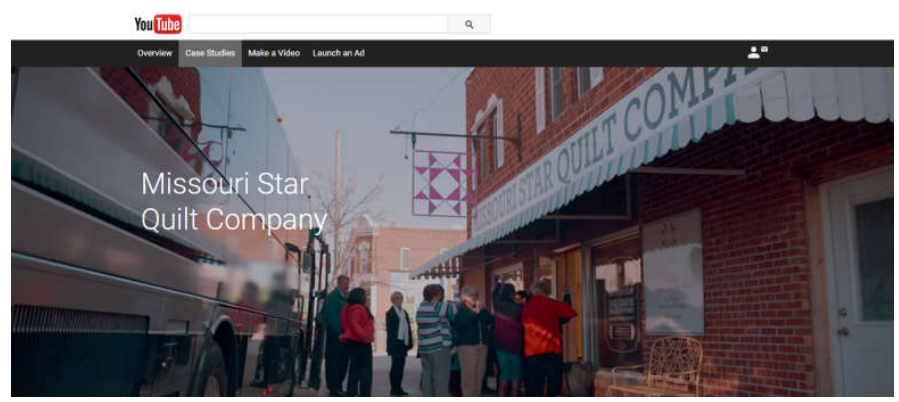

Image 1 - Missouri Star Quilt Company

RevZilla had 7 millions of video shows and increased its income by $50 \%$ since the last year. RevZilla is one of e-commerce sites in Philadelphia. It sells high-end motor equipment such as jackets, clothes, helmets, and other accessories. Through videos and YouTube Advertisement, RevZilla team could serve the customer better and reached more of them by 
showing new products and safety riding tips. This approach had managed to attract so many motor users (YouTube, 2017b).

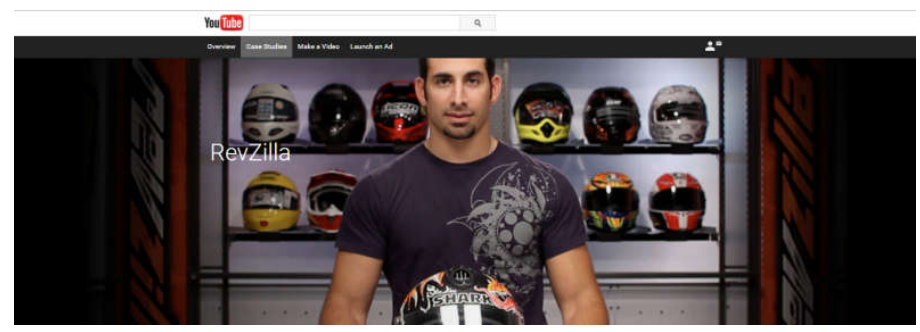

Image 2 - RevZilla

LSTN Headphones used YouTube Advertisement as a means to introduce its products globally. Its popularity had made LSTN Headphones capable of giving gifts to more than 20,000 people around the world (YouTube, 2017c).

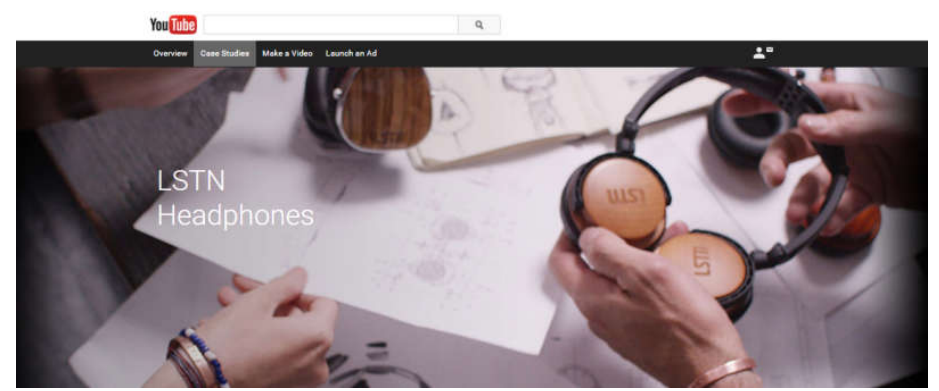

Image 3 - LSTN Headphones

Using of Facebook Advertisement. Heineken Taiwan is one of international premium beer brands. It used Facebook live to show live concerts and encouraged online participation through music campaign. Therefore, it could increase its brand value among Taiwan music lovers. The increase of market share within three months after the using of Facebook Advertisement is 100 basist points. It also managed to increase its sale as much as $4 \%$ compared to the previous year and received Brand Equity Score of 8.66 (Facebook, 2017a).

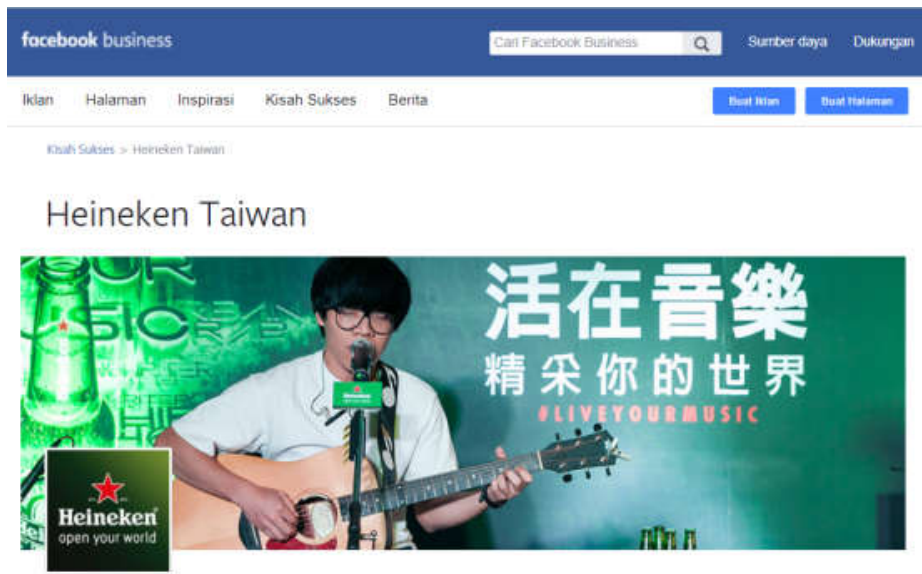

Image 4 - Heineken Taiwan

Lazada is one of e-commerce with market range of some countries such as Indonesia, Malaysia, Singapore, Thailand, and Vietnam. It used Facebook Advertisement as the means of promotion. The using of Facebook Advertisement could increase the orders by more than $59 \%$ and the advertisement awareness as much as 15\% (Facebook, 2017b). 


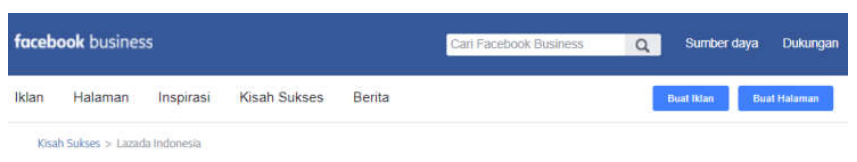

Lazada Indonesia

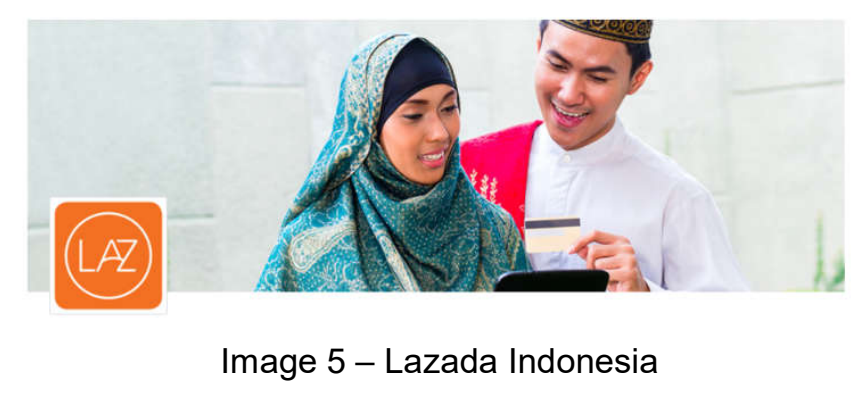

Carousell is one of successful e-commerce sites that used Facebook Advertisement. Using video as the means of promotion, it could attract a large number of viewers so that new seller is increasing 2.6 times each month. Besides that, product offering is increasing by $53 \%$ and the action cost for promotion is decreased as much as 57\% (Facebook, 2017c).

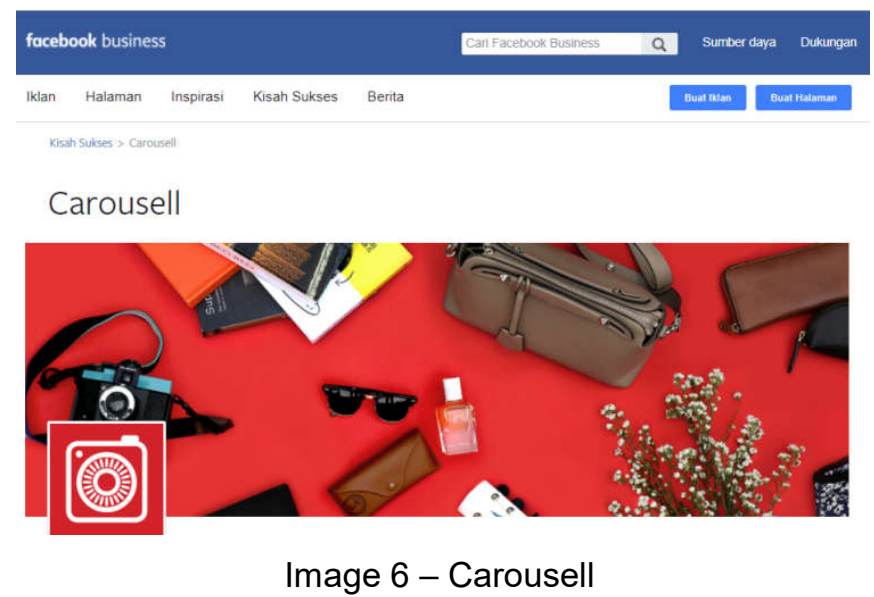

YouTube and Facebook Advertisement. YouTube is a video share service which is mostly used around the world. It is a part of Google that contributes $26.15 \%$ of global broadband traffic (Cisco, 2010). Before making an advertisement in YouTube, a user should firstly have a Google account. Once a Google account had been created, it will be automatically synchronized to YouTube.

Facebook is famous social networking site in Indonesia which has hundreds of million users around the world, who are connected one to another. Facebook has many facilities that could be used by its users, such as fans page and advertising to enhance goods and service business (Aljawiy and Muklason, 2011).

Effectiveness of YouTube and Facebook Advertisement. In Facebook, advertisement could be placed in pre-roll, mid-roll, and post-roll (Krishnan and Sitaraman, 2013). Pre-roll is the placement of advertisement in first view. Commonly in YouTube, advertisement will be viewed for 5 seconds or more, depends on the user's setting. Mid-roll is the placement of advertisement in the middle of viewed video duration. Post-roll is the advertisement that is viewed after the main video ends. Generally, advertisement is often viewed by pre-roll or mid-roll because the advertisement will be viewed directly before the viewers watch a YouTube video.

However, a YouTube advertisement has a really big weakness that is when the browser is installed by AdBlock. The advertisement won't be viewed because it had been already blocked by a particular program that blocks the advertisement such as AdBlock Plus. This program is now the most popular that is used by users of web browsers such as Mozilla 
Firefox and Google Chrome (Pujol, 2015). There are some arguments that said an advertisement is very annoying so that they installed Adblock in their browsers.

In this digital era, a Smartphone has nearly same function as a computer. It can be used to access YouTube and Facebook. The usage of Adblock in Smartphones are still low so that YouTube Advertisement is however still effective as the means of promotion. The usage of Adblock in browser is also low because it's only used by people who are annoyed by the advertisement.

Facebook Advertisement has various choices to make a promotion, other than video. Advertisement could be adjusted according to the user's needs in promoting their advertisement.

Using Facebook Advertisement is increasing the opportunity of advertisement's success, because it's not affected by Adblock Plus that had been installed in the browser. The advertisement will be easily viewed in the News Feeds and is not going to be blocked by Adblock application.

Maximizing the Usage of YouTube and Facebook Advertisement. There are some things that should be concerned in order to be successfully advertising in YouTube according to Tutorials Point (2016).

Shareable - Will viewers share your videos? The advertisement should be able to attract people's interest in sharing to other social media. This will ease the distribution of advertisement to the consumer. It also reduces the advertisement cost, because shared videos are not included to advertisement cost. Interesting and unique content will be viral instantly and will gain more viewers. Besides that, a viral content will fasten the sharing rate to other social media users.

Conversational - Is there an element of speaking directly to the audience? The most important element in interesting video advertisement is it should be able to make the viewer feels the situation of the advertisement. The audio in video advertisement should be able to make the viewer experience the situation, so that the advertisement will be always remembered. For example, a mineral water advertisement includes the sounds of splashing water in the mountains, supported by green natural scenery. This situation will make the viewer feels and think that the mineral water is really refreshing.

Interactive - Can the audience interact with the content? An interesting advertisement should be able to communicate directly with its viewers. It is just like the actor in that advertisement communicates directly to the viewers. For example in health equipment advertisement, an actor talks about the common problems of health that may be experienced by the viewers. It is as if the actor talks directly to the viewer, so that the viewer will feel the presence of communication with that actor. If this is done repeatedly, the viewer will get information from that product.

Consistent - Are there consistent elements to each episode? An advertisement should be consistent to show that the advertisement is related to the previous one. This will enhance the understanding about the advertisement and increase the attractiveness. If the advertisement is showed in form of episodes, the advertisement must be consistent with the previous. A serial advertisement will make the viewer curious and wait for the continuation.

Targeted - Is there a distinct audience your videos are targeting? Targeting is important in order to get suitable target of advertisement. If the business range is only includes a province, then the advertisement priority should be made in the province first. If the product had been known in the desired province, then the range can be widened. Advertisement target should be well determined so that suitable target can be reached and advertisement cost can be minimized.

Discoverable - Will viewers discover your videos through search? Most accessed video advertisement is the one that sits in top 10 position of Google search engine. It also happens when the key words of YouTube search is included to the suggested search. People are more likely to click the video in the first search result page, so that the video in the first page will be able to increase its popularity quickly.

Accessible - Can a new viewer appreciate every episode? Every new advertisement should be designed as good as the creator can, so that the viewer will be more appreciate it. 
The form of appreciation could be positive comments, likes, and shared advertisements to other friends in the social media.

Sustainable - If your audience loves it, can you make more of it? If the viewers had already liked the uploaded video, that doesn't mean the creator can stop at the point. It is the creator's responsibility to increase advertisement's quality and attract new viewers by uploading consistent, innovative, and creative new videos.

Collaborative - Is there space for guests in your episodes? Collaboration of every episode is needed in order to get suggestions and critiques through provided contact person. Arguments, suggestions, and critiques on the video will be a new strength to make a better advertisement video. Because of that, guest room is needed in the making of advertisement video.

Inspired - Are your videos coming from a place of true passion? Background of popular places will add the attractiveness of the video. For example, a perfume advertisement is made by using Eiffel Tower in Paris as background to add the romantic effect. This will be better than if the background is somewhere less romantic such as a desert.

Below is some guide to design an advertisement so that it always have a good quality and appears everywhere in the social media. The guide is as follows (Facebook, 2017d).

1. Text: 90 characters;

2. Aspect ratios supported: $16: 9$ (full landscape) to $9: 16$ (full portrait) Mobile in feed: Videos will be rendered "as is" up to $2: 3$, with masking to $2: 3$ for aspect ratios of between $2: 3$ and 9:16;

3. Desktop in feed and desktop player: For desktop in feed, vertical video will continue to be letterboxed to $1: 1$. For the desktop player, vertical video will be $9: 16$ with no black-bar letterboxing;

4. Recommended aspect ratio for vertical video: 9:16 (full portrait), ensuring that core content falls within the $2: 3$ mask for mobile News Feed;

5. Video: H.264 video compression, high-profile preferred, square pixels, fixed frame rate, progressive scan;

6. Format: .mp4 container, ideally with leading MOOV atom, no edit lists;

7. Audio: Stereo AAC audio compression, $128 \mathrm{kbps}+$ preferred.

\section{CONCLUSION}

The using of YouTube and Facebook Advertisement are indeed proven to increase sales and promotion target, and also reduce the advertisement cost. However, the presence of program that blocks the advertisement of Google's products had made Facebook a little bit more superior than YouTube Advertisement. But, in this digital era there are still many people who don't understand the usage of Adblock program, especially in Smartphone where the usage of Adblock is still very low. Therefore, YouTube Advertisement is still highly recommended as the means of digital promotion. The using of YouTube and Facebook Advertisement is highly recommended because of their large number of users around the world.

\section{REFERENCES}

1. Aljawiy, A. Y. dan Muklason, A., 2011. Jurnal Ilmiah "Teknologi": Jejaring Sosial Dan Dampak Bagi Penggunanya, Program studi Sistem Informasi Unipdu, Jombang

2. Cisco (2010). Cisco visual networking index: Usage study. Retrieved from http://www.cisco.com/en/US/solutions/collateral/ns341/ns525/ns537/ns705/Cisco_VNI_U sage_WP.html

3. Facebook. 2017a. Facebook Bussines: Heineken Taiwan. Retrieved 6 27, 2017, https://www.facebook.com/business/success/heineken-taiwan

4. Facebook. 2017b. Facebook Bussines: Lazada Indonesia. Retrieved 6 27, 2017, https://www.facebook.com/business/success/lazada-indonesia 
5. Facebook. 2017c. Facebook Bussines : Carousell. Retrieved 6 27, 2017, https://www.facebook.com/business/success/carousell

6. Facebook. 2017d. Facebook Advertisement Guide. Retrieved 6 27, 2017, https://www.facebook.com/business/Advertisementguide/?tab0=Mobile $\% 20$ News $\% 20 F e e d$

7. Facebook. 2017e. Facebook Bussines: Buat Iklan di Pengelola Iklan. Retrieved 627 , 2017, https://www.facebook.com/business/help/633662000000451/?helpref=hc_fnav

8. Fitzgerald, J. (2015). SMK. (SMK Insight) Retrieved 6 27, 2017, from 2015 Social Media Trends \& Opportunities: https://smk.co/files/reports/SMK_SocialMediaTrends_2015.pdf

9. Google. 2017. AdWords Help: About TrueView video campaigns. Retrieved 6 27, 2017, https://support.google.com/adwords/answer/6381008

10. Graham, S., \& Curran, C. T. K. (2011). Advertising on Facebook. International Journal of E-Business Development (IJED), 1(1), 26-33.

11. Hancock B., Windridge K., \& Ockleford, E. 2007. An Introduction to Qualitative Research. The NIHR RDS EM / YH.

12. Kangas, P. (2007). " Advertisement by Google" and Other Social Media Business Models. VTT.

13. Krishnan, S. S., \& Sitaraman, R. K. (2013, October). Understanding the effectiveness of video Advertisement: a measurement study. In Proceedings of the 2013 conference on Internet measurement conference (pp. 149-162). ACM.

14. Machfoedz, M. 2010. Komunikasi Pemasaran Modern. Yogyakarta: Cakra IImu.

15. Pujol, E., Hohlfeld, O., \& Feldmann, A. (2015, October). Annoyed users: Advertisement and ad-block usage in the wild. In Proceedings of the 2015 ACM Conference on Internet Measurement Conference (pp. 93-106). ACM.

16. Tutorials Point, 2016. YouTube Marketing. Retrieved on June 27, 2017, https://www.tutorialspoint.com/YouTube_marketing/YouTube_marketing_tutorial.pdf

17. Yin, R. K. 2011. Qualitative Research from Start to Finish. New York: The Guilford Press.

18. YouTube. 2017a. Missouri Star Quilt Company. Retrieved on June 27, 2017, https://www.YouTube.com/yt/advertise/case-study-missouri-star-quilt-co.html

19. YouTube. 2017b. RevZilla. Retrieved on June 27, 2017, https://www.YouTube.com/yt/advertise/revzilla.html

20. YouTube. 2017c. LSTN Headphones. Retrieved on June 27, 2017, https://www.YouTube.com/yt/advertise/case-study-lstn.html 